\title{
Burnout and Job Stress among Mongolian Doctors and Nurses
}

\author{
Ariunsanaa BAGAAJAV1, Sugarmaa MYAGMARJAV1, Khuderchuluun NANJID², \\ Saranchuluun OTGON ${ }^{1}$ and Young Moon CHAE $^{3 *}$
}
${ }^{1}$ Department of Social Sciences and Humanities, School of Public Health, Health Sciences University, Mongolia
${ }^{2}$ Department of Epidemiology and Biostatistics, School of Public Health, Health Sciences University, Mongolia
${ }^{3}$ Department of Health Informatics, Institute of Health Services Research, Graduate School of Public Health, Yonsei University, \#134, Sinchon-dong, Seodaemun-ku, Seoul 120-752, Korea

Received November 17, 2010 and accepted April 5, 2011

Published online in J-STAGE August 1, 2011

\begin{abstract}
Due to the inherent demands of their profession, doctors and nurses are at great risk of suffering from burnout caused by job stress. This study examined the prevalence of burnout among doctors and nurses in Mongolia and identified the factors influencing their burnout. A self-administered questionnaire of 180 doctors $(45.9 \%)$ and 212 nurses $(54.1 \%)$ resulted in a response rate of $87 \%$. Burnout was measured by the Copenhagen Burnout Inventory (CBI) in three scales: personal burnout, work-related burnout, and client-related burnout. Job stress was measured by the effort-reward imbalance (ERI) model. Compared with the prior studies of hospital staffs in other countries, doctors and nurses in Mongolia had relatively higher burnout rates, with personal, work-related and client-related average scores of 45.39, 44.45, and 32.46, respectively. Multiple regression analysis revealed that ERI significantly influenced all dimensions of burnout but over-commitment significantly influenced only personal and workrelated burnout. Both ERI and over-commitment were different among professions.
\end{abstract}

Key words: Copenhagen Burnout Inventory, Effort-reward imbalance, Mongolia

\section{Introduction}

As a result of the sweeping socio-economic transition that commenced in 1990, Mongolian health care management and service delivery systems were dramatically reorganized. Numerous new programs were implemented, such as a compulsory national health insurance system, a primary health care strategy and family medicine. Unlike the republics of the Former Soviet Union, the Mongolian health care system had been overseen by the government health sector without any community involvement or participation. Therefore, the health care system was predominately focused on specialty services with an inflated number of hospitals, beds and specialist

*To whom correspondence should be addressed.

E-mail: ymchae@yuhs.ac physicians. This resulted in high health care expenditure, even as measured health status remained poor ${ }^{1}$. This prompted a greater emphasis on preventive rather than curative health care and a shift from large hospitals to primary health care ${ }^{2)}$. Similar to experiences in other countries, transitioning health strategies result in higher costs or lower overall levels of service until cost efficiencies can be realized. This has been problematic in Mongolia where per capita government expenditure on health care has fallen by approximately 40 percent between 1991 and 19962).

Today healthcare system in Mongolia is characterized by 3 levels of care and its prevailing principle is to deliver equitable, accessible, and quality health care and services for each citizen. Primary care and services are mainly placed in family practice facilities, secondary care and services take place in general hospitals, and 
tertiary service is placed $^{3}$. Unlike other countries, doctors and nurses account for a large proportion of health professionals in the health care sector and they are the main health care providers. In 2009, of 38,704 total professionals working in healthcare, 7,140 were doctors and 9,017 were nurses ${ }^{3)}$.

In Ulaanbaatar, several factors may indicate increasing stress levels in doctors. Despite regulations establishing a daily maximum of 15 patients, Ulaanbaatar primary care physicians treat 40 to 50 patients per day, which is compounded by an obligation to treat unregistered migrants from rural areas without payment. Maternity doctors treat 27 patients a day in inpatient care and 12 in outpatient clinics ${ }^{4}$. Internal medicine physicians feel that the consequence of this increased workload leads to neglect and needs to be seriously addressed. In addition, each patient encounter requires higher physician input due to such tasks as counseling the patient and family members. Furthermore, surgeons typically work 4-8 night shifts a month, as well as an additional 3-4 urgent surgery calls that are not compensated by either time or remuneration ${ }^{3)}$. Pediatric physicians are of special concern since there is a profound demand and scarce supply. In the previous study on pediatricians ${ }^{4}$, participants from the focus group discussions indicated that many pediatricians who recently started working have quit their job within 1-4 yr. Compared to other specialists, the same study indicated that pediatricians spend twice as much time on medical checks, which may increase their susceptibility to burnout. In addition, $10.5 \%$ had sought help from professional psychologists due to stress of their practice and another $28.6 \%$ of them had intended to do so.

Burnout and job stress are important issues for health care professionals because they cause significant risk to their health and well being ${ }^{5)}$. These properties have been studied and recognized since 1970 in the fields of mental health and health psychology6). However, despite such wide recognition, particularly in Western societies ${ }^{7)}$, very few investigations have been conducted in Asia regarding burnout. Several studies ${ }^{8,9)}$ reported that stress at work has become a significant concern to public health in view of the damage it causes to workers, companies and society as a whole. In addition, studies have shown that burnout causes poor mental health, sometimes forcing physicians to quit their work ${ }^{10)}$. In Mongolia, excessive workload has degraded physician's attitude towards work and is therefore a significant source for developing burnout, job stress and job dissatisfaction ${ }^{4}$. Accordingly, prevention of burnout among health professionals is essential to the provision of high quality health care.

The concept of burnout started as a "grassroots" description of prolonged occupational stress among human service workers, where employees gradually get overwhelmed by emotional exhaustion, loss of energy, and withdrawal from work. The most widely used instrument for measuring burnout is the Maslach Burnout Inventory (MBI), from which the MBI- General Survey and the Burnout Measure were developed. In 1997, a Danish study group developed a new instrument for measuring burnout, the Copenhagen Burnout Inventory $(\mathrm{CBI})$ in the frame of the PUMA study which was established as a longitudinal intervention study on burnout, and its causes and distribution over $5 \mathrm{yr}$. In accordance with the historical development of the burnout concept, the CBI focuses on exhaustion. The key feature is the attribution of exhaustion to three specific domains: general exhaustion experienced by person, exhaustion attributed to work and exhaustion attributed to work with clients ${ }^{11)}$. The CBI was used in the present study instead of the MBI because the major reason for burnout for Mongolian doctors and nurses seemed to be exhaustion from heavy workload. We also chose the effort-reward imbalance (ERI) model, which is considered one of the most valid and reliable instrument for measuring job stress. This model has been widely tested among various types of professionals, including doctors and nurses ${ }^{12-16)}$.

This study was conducted to explore job stress and its association with burnout among doctors and nurses. The specific purposes were to determine the sociodemographic factors and job characteristics related to burnout, to identify the factors influencing burnout, and to compare burnout and stress level among health professionals. It is hoped that the findings will support the development of effective interventions to reduce stress and burnout for health professionals in Mongolia.

\section{Subjects and Methods}

\section{Study population}

The study population comprised doctors and nurses from five major clinical hospitals and four district clinics. A total of 392 participants (180 doctors and 212 nurses) responded to a self-administered questionnaire distributed to 450 doctors and nurses in Ulaanbaatar, with a response rate of $87 \%$. The study participants were recruited in August, 2009. Researchers provided a briefing about the study objectives as well as statements guaranteeing both the confidentiality and anonymity of responses.

\section{Measurements}

The questionnaire contained scales for measuring burnout and job stress. Age, gender, and marital status 
were chosen as socio-demographic factors and income, type of housing, monthly salary and household income as socio-economic factors. Burnout was measured by the $\mathrm{CBI}^{11)}$ including three dimensions of burnout: personal, work-related, and client-related burnout. Personal burnout contained five items on general symptoms of exhaustion; work-related burnout contained seven items on symptoms of exhaustion related to work; and workrelated burnout contained five items on symptoms of exhaustion referring to working with clients. All items used a Likert-type, five-response category scale. The responses were rescaled to a 0-100 metric and the scales have demonstrated high face validity and criterion validity ${ }^{11)}$. The questionnaire has also been shown to have Cronbach's $\alpha$ coefficient for each dimension of $0.78,0.82$, and 0.87 , respectively. For the analysis, we used continuous variables of the scales. A high burnout score is an indication of high burnout.

Job stress was assessed by the ERI model, comprising 23 items ${ }^{13)}$. To measure efforts, six items related to psychologically and physically demanding aspects of the work environment were surveyed (Cronbach's $\alpha$ was 0.81). The measurement of reward focused on six rewards received at work and offered to the worker as part of a social exchange process in the form of monetary remuneration, social approval and esteem, job security, and career opportunities. Measurement of reward was based on a further 11 items (Cronbach's $\alpha$ was 0.80). In addition, measurement of over-commitment was based on 6 items on 4 point Likert scale. To measure the effort-reward imbalance (ERI), the ratio of effort scale score (numerator) and reward scale score (denominator) was calculated according to standard procedures. For the job characteristic variables, we included work for extra hours, a number of years in the current position and a number of patients served per day. Confounding variable was a stressful life event that had occurred within the previous 12 months.

\section{Statistical analysis}

$\chi^{2}$ test was used for analyzing the association between profession and categorical variables including gender, marital status, type of housing, and work for extra hours. The independent $t$-test was used for comparing continuous variables including age, monthly salary, number of years employed in current position and number of patients served per day. The independent $t$-test was also applied to compare the means of job stress including ERI, over-commitment, and burnout dimension burnout between doctors and nurses. Correlation analysis was performed to analyze the relationships among independent variables influencing burnout in order to avoid multi-collinearity problem in the multiple regression analysis. Multiple regression analysis was performed to identify the factors influencing three burnout dimensions. For the analysis, categorical variables such as marital status, profession, work for extra hours, and stressful life event were transformed into dummy variables. Analysis of covariance (ANCOVA) with age as covariate was used to compare the means of components of job stress (ERI and overcommitment) and burnout dimensions (personal, workrelated and client-related burnout) by gender and profession. Of the four male nurses in the study population, two were among the 28 cases of incomplete responses that were excluded before running the ANCOVA. With only two samples remaining, we decided not to include male nurses, leaving 362 cases to be included in the analysis. The Tukey's Honestly Significant Difference (HSD) post-hoc multiple comparison test was applied to compare the differences between the groups. All calculations were performed using SPSS 12, with the level significance set at $p<0.05$.

\section{Results}

Selected socio-demographic, socio-economic, and job characteristics of the doctors and nurses were summarized in Table 1. The mean age was $37.5 \mathrm{yr}$. Percentage of single was higher for nurses than doctors, possibly due to their younger age. According to the type of housing, the majority of doctors $(79.8 \%)$ lived in their own private apartment while about a quarter of the nurses $(26.8 \%)$ lived in rented apartments or "Ger" which is the traditional tent-like dwelling of the nomads in Mongolia. The average monthly salary was 237,000 Mongolian tugrug (MNT), approximately 185 USD and was significantly higher for the doctors (260,000 MNT) than for nurses $(217,960)$. This difference was even greater for household income. The doctors $(82.6 \%)$ significantly worked more overtime hours than nurses $(70.8 \%)$. There were no significant differences between the two professions in age, length of employment in their current position $(10 \mathrm{yr})$, and number of patients treated daily ( 27 patients).

Results of correlation analysis for the factors related to burnout were summarized in Table 2. These factors were used as independent variables for the multiple regression. ERI was significantly related to overcommitment, age, profession, extra work, and stressful life event. Over-commitment was significantly related to ERI, income, profession, extra work, and stressful life event. Unexpectedly, ERI and over-commitment were not significantly related to the number of patients. Profession was significantly related to ERI, overcommitment, marital status, income, and the number of 
Table 1. Socio-demographic and job characteristics for health professionals

\begin{tabular}{|c|c|c|c|c|c|c|c|}
\hline \multirow{3}{*}{ Variable } & \multirow{2}{*}{\multicolumn{2}{|c|}{ Total }} & \multicolumn{4}{|c|}{ Profession } & \multirow{3}{*}{$p$-value } \\
\hline & & & \multicolumn{2}{|c|}{ Doctor } & \multicolumn{2}{|c|}{ Nurse } & \\
\hline & $\mathrm{n} /$ mean & $\% / \mathrm{SD}$ & $\mathrm{n} /$ mean & $\% / \mathrm{SD}$ & $\mathrm{n} /$ mean & $\% / \mathrm{SD}$ & \\
\hline Age & 37.5 & 8.6 & 38.3 & 8.03 & 37.2 & 9.23 & $0.230^{\mathrm{c}}$ \\
\hline Gender & & & & & & & $0.000^{\mathrm{b}}$ \\
\hline Male & 37 & $9.5 \%$ & 33 & $18.5 \%$ & 4 & $1.9 \%$ & \\
\hline Female & 351 & $90.5 \%$ & 145 & $81.5 \%$ & 206 & $98.1 \%$ & \\
\hline Marital status & & & & & & & $0.008^{b}$ \\
\hline Single & 74 & $18.9 \%$ & 23 & $12.8 \%$ & 51 & $24.1 \%$ & \\
\hline Married & 267 & $68.1 \%$ & 136 & $75.5 \%$ & 131 & $61.8 \%$ & \\
\hline Miscellaneous $^{\mathrm{a}}$ & 51 & $13.0 \%$ & 21 & $11.7 \%$ & 30 & $14.1 \%$ & \\
\hline Type of housing & & & & & & & $0.000^{\mathrm{a}}$ \\
\hline Apartment & 200 & $51.1 \%$ & 143 & $79.9 \%$ & 57 & $26.9 \%$ & \\
\hline Ger and rent apartment & 191 & $48.9 \%$ & 36 & $20.1 \%$ & 155 & $73.1 \%$ & \\
\hline Monthly salary $(\mathrm{MNT})^{\mathrm{d}}$ & 237.17 & 46.02 & 260.06 & 46.37 & 217.96 & 35.9 & $0.000^{c}$ \\
\hline Household income & 496.27 & 242.64 & 588.21 & 256.27 & 416.55 & 198.85 & $0.000^{\mathrm{b}}$ \\
\hline Work for extra hours & & & & & & & $0.006^{\mathrm{b}}$ \\
\hline No & 92 & $23.7 \%$ & 31 & $17.3 \%$ & 61 & $29.2 \%$ & \\
\hline Yes & 296 & $76.3 \%$ & 148 & $82.7 \%$ & 148 & $70.8 \%$ & \\
\hline Years employed $^{\mathrm{e}}$ & 9.93 & 8.94 & 9.02 & 7.87 & 10.7 & 9.71 & $0.067^{c}$ \\
\hline Number of patients & 27.38 & 20.68 & 25.47 & 19.64 & 29.04 & 21.45 & $0.092^{\mathrm{c}}$ \\
\hline
\end{tabular}

${ }^{\mathrm{a}}$ Miscellaneous: cohabiting, divorced, widow, ${ }^{\mathrm{b}} \chi^{2}$ test, ${ }^{\mathrm{c} I n d e p e n d e n t} t$-test, ${ }^{\mathrm{d}} 1,000$ Mongolian tugrug (MNT), ${ }^{\mathrm{e}}$ Years employed in the current job.

Table 2. Results of correlation analysis for the factors related to burnout

\begin{tabular}{|c|c|c|c|c|c|c|c|c|c|}
\hline & ERI & Over-commitment & Age & $\begin{array}{l}\text { Marital } \\
\text { status }\end{array}$ & Income & Profession & $\begin{array}{l}\text { No. of } \\
\text { patients }\end{array}$ & $\begin{array}{l}\text { Extra } \\
\text { work }\end{array}$ & $\begin{array}{l}\text { Life } \\
\text { event }\end{array}$ \\
\hline ERI & 1.00 & & & & & & & & \\
\hline Over-commitment & $0.49 * *$ & 1.00 & & & & & & & \\
\hline Age & $-0.11 *$ & -0.08 & 1.00 & & & & & & \\
\hline Marital status & 0.04 & -0.05 & $-0.29 * *$ & 1.00 & & & & & \\
\hline Income & -0.05 & $0.12 *$ & -0.04 & -0.05 & 1.00 & & & & \\
\hline Profession & $0.14 * *$ & $0.24 * *$ & 0.10 & $-0.10 *$ & $0.36 * *$ & 1.00 & & & \\
\hline No. of patients & -0.03 & -0.09 & -0.07 & 0.41 & -0.06 & $0.11^{*}$ & 1.00 & & \\
\hline Extra work & $0.21 * *$ & $0.23 * *$ & $-0.13 *$ & 0.003 & 0.06 & $-0.16^{* *}$ & $0.20 * *$ & 1.00 & \\
\hline Life event & $0.16^{* * *}$ & $0.20 * *$ & -0.003 & 0.02 & 0.004 & 0.01 & -0.03 & 0.06 & 1.00 \\
\hline
\end{tabular}

$*: p<0.05, * *: p<0.01$.

patients. Finally, extra work was significantly related to ERI, over-commitment, age, profession, and the number of patients.

As seen in Table 3, ERI, over-commitment, and profession significantly influenced personal burnout; ERI, over-commitment, and stressful life event significantly influenced work-related burnout; and ERI and the number of patients significantly influenced clientrelated burnout. Only ERI significantly influenced all three dimensions of burnout. As seen in the correlation analysis, doctors and nurses have significantly different personal characteristics such as ERI, over-commitment, marital status, income, number of patients, and extra work. This may explain the fact that profession signifi- cantly influenced personal burnout. Stressful life events that occurred within the previous 12 months were significantly associated with work-related burnout, implying that work performance is likely to be influenced if the doctors and nurses face tension or pressure from personal life event. R-square for client-related burnout (0.18) was lower than other burnout dimensions and only ERI was significant factor.

Means and standard deviations for each ERI and burnout dimensions were compared among three groups (male doctors, female doctors, female nurses) in Table 4. After adjusting for age, we found significant differences in all scales except for personal and work-related burnout. Female doctors suffered from the highest degree 
Table 3. Results of regression analysis for burnout

\begin{tabular}{|c|c|c|c|c|c|c|c|c|c|}
\hline & \multicolumn{3}{|c|}{ Personal burnout } & \multicolumn{3}{|c|}{ Work-related burnout } & \multicolumn{3}{|c|}{ Client-related burnout } \\
\hline & Reg. coeff. & Beta & $p$ value & Reg. coeff. & Beta & $p$ value & Reg. coeff. & Beta & $p$-value \\
\hline Constant & 13.13 & & & 17.15 & & & 11.69 & & \\
\hline \multicolumn{10}{|l|}{ Job stress } \\
\hline ERI & 20.39 & 0.35 & $<0.001$ & 26.1 & 0.42 & $<0.001$ & 25.92 & 0.38 & $<0.001$ \\
\hline Over-commitment & 1.30 & 0.28 & $<0.001$ & 1.27 & 0.25 & $<0.001$ & 0.37 & 0.06 & 0.3 \\
\hline \multicolumn{10}{|l|}{ Socio-demographics } \\
\hline Age & -0.07 & -0.04 & 0.52 & -0.14 & -0.06 & 0.18 & -0.06 & -0.03 & 0.63 \\
\hline Marital status* & 0.70 & 0.02 & 0.72 & -2.59 & -0.06 & 0.19 & -1.05 & -0.02 & 0.68 \\
\hline Income & -0.001 & -0.005 & 0.93 & -0.01 & -0.07 & 0.16 & 0.01 & 0.05 & 0.33 \\
\hline \multicolumn{10}{|l|}{ Job characteristics } \\
\hline Profession* & 5.34 & 0.16 & 0.004 & 1.83 & 0.05 & 0.34 & -1.95 & -0.05 & 0.43 \\
\hline Number of patients & -0.04 & -0.06 & 0.28 & -0.06 & -0.08 & 0.11 & 0.1 & 0.11 & 0.05 \\
\hline Extra work* & -1.20 & -0.03 & 0.57 & 1.15 & 0.02 & 0.61 & -1.77 & -0.04 & 0.54 \\
\hline Stressful life event* & 1.58 & 0.05 & 0.36 & 1.27 & 0.25 & $<0.001$ & -2.61 & 0.06 & 0.24 \\
\hline R square & 0.32 & & & 0.38 & & & 0.18 & & \\
\hline F test & & $\begin{array}{c}13.91 \\
(p<0.01)\end{array}$ & & & $\begin{array}{c}18.95 \\
(p<0.01)\end{array}$ & & & $\begin{array}{c}6.83 \\
(p<0.01)\end{array}$ & \\
\hline
\end{tabular}

Table 4. Means and SDs for ERI scale and burnout dimensions by gender and profession

\begin{tabular}{|c|c|c|c|c|c|c|c|c|c|}
\hline & \multicolumn{2}{|c|}{$\begin{array}{l}\text { Male MD } \\
(\mathrm{n}=31)\end{array}$} & \multicolumn{2}{|c|}{$\begin{array}{l}\text { Female MD } \\
(\mathrm{n}=128)\end{array}$} & \multicolumn{2}{|c|}{$\begin{array}{l}\text { Female nurses } \\
\quad(\mathrm{n}=199)\end{array}$} & \multirow{2}{*}{$p$-value } & \multicolumn{2}{|c|}{$\begin{array}{c}\text { Total } \\
(\mathrm{n}=362)\end{array}$} \\
\hline & Mean & SD & Mean & SD & Mean & SD & & Mean & $\mathrm{SD}$ \\
\hline Effort & 12.03 & 3.88 & 13.49 & 3.79 & 11.72 & 3.69 & 0.000 & 12.38 & 3.82 \\
\hline Reward $^{\mathrm{a}}$ & 47.75 & 5.75 & 45.44 & 5.86 & 47.35 & 5.92 & 0.006 & 46.70 & 5.94 \\
\hline ERI $^{\mathrm{a}}$ & 0.58 & 0.29 & 0.68 & 0.28 & 0.57 & 0.27 & 0.002 & 0.61 & 0.28 \\
\hline Over-commitment & 13.60 & 3.97 & 13.64 & 3.47 & 14.96 & 3.42 & 0.002 & 14.36 & 3.54 \\
\hline Personal burnout & 39.33 & 17.99 & 45.35 & 16.10 & 44.92 & 16.61 & 0.158 & 44.61 & 16.57 \\
\hline Work-related burnout & 40.36 & 18.43 & 46.82 & 18.28 & 43.24 & 17.78 & 0.059 & 44.28 & 18.08 \\
\hline Client-related burnout ${ }^{\mathrm{a} b}$ & 25.86 & 19.23 & 36.31 & 19.89 & 30.33 & 19.72 & 0.004 & 32.14 & 19.97 \\
\hline
\end{tabular}


(Multiple Comparisons, Tukey's HSD).

of ERI (0.68) and the higher degree of all three burnout dimensions. Specifically, female doctors had significantly higher ERI and client-related burnout than female nurses; and significantly higher client-related burnout than male doctors based on Tukey's HSD post-hoc test. But female nurses had the highest degree of overcommitment (14.96) and it was significantly higher than female doctors.

\section{Discussion}

This study examined the prevalence of burnout among doctors and nurses in Mongolia and identified the factors influencing their burnout. Regression results showed that ERI significantly influenced all dimensions of burnout. Over-commitment significantly influenced both personal and work-related burnout but did not significantly influence client-related burnout. Similar results were reported in the studies conducted in Asian countries, specifically in Japan ${ }^{12,}{ }^{15)}$ and China ${ }^{16)}$. Odagiri et al. ${ }^{17)}$ found that both ERI and over-commitment significantly influenced burnout for nurses. In a study among Chinese judicial officers and procurators, ERI and over-commitment were significantly associated with both personal and work-related burnout ${ }^{18)}$.

We found that profession significant influenced personal burnout perhaps due to differences in personal characteristics between doctors and nurses. Correlation analysis in Table 2 revealed that profession was significantly related to personal characteristics such as ERI, over-commitment, marital status, income, and the number of patients. In addition, there were significant differences in ERI and over-commitment, which were two important factors for personal burnout, between 
female doctor and female nurses. The previous study ${ }^{11)}$ reported that over-commitment was considered to be an intrinsic personal factor and overcommitted people were susceptible to exhaustion. Hasselhorn et al. ${ }^{19)}$ also found a similar results on job stress and burnout among the nurses in transition countries.

As seen in Table 4, average scores for personal, workrelated and client-related burnout were 44.61, 44.28, and 32.14 , respectively. Especially, female doctors had the highest burnout scores: 45.35, 46.82, and 36.31. These results were higher than those reported by Kristensen et al., which were $36.6,39.8$, and 26.7 for doctors and $36.9,35.0$ and 29.7 for nurses, respectively ${ }^{11)}$. In this study, ERI scores were $0.58,0.68$, and 0.57 for male doctors, female doctors, and female nurses, respectively. $\mathrm{Li}^{16)}$ et al. found that ERI for male doctors, female doctors and female nurses in China were 0.72, 0.59, and 0.66 , respectively. High ERI score for female doctors in this study may be attributed to the domination of the health care delivery system by female professionals in Mongolia ${ }^{4}$. Female nurses were more over-committed than female doctors perhaps because nurses were caring more patients than doctors, even though difference was not significant.

This is the second effort to apply ERI scale in Mongolia, the previous studies were conducted for Mongolian civil servants ${ }^{20,21)}$. However, a major different feature of our study was that we used CBI for the first time in Mongolia. The CBI has been translated into a number of languages (English, Japanese, Mandarin, Swedish, Finnish, French etc.). The CBI has been compared with the MBI for some of the CBIusers with encouraging results. In the Australian study on burnout among dentists, Winwood and Winefield ${ }^{22}$ compared the CBI with the MBI and concluded that the CBI possesses excellent psychometric properties and seems to be an appropriate measure of burnout in populations of health professionals ${ }^{11)}$. The scales used in the study have high validity in European countries and therefore we used the same scales in Mongolia.

Reviews of the burnout literature documented that burnout results from exposure to chronic job stress ${ }^{23)}$. This study also revealed that job stress strongly influenced burnout and therefore special stress management program should be implemented to reduce burnout at hospitals in Mongolia. There are number of options to consider in looking at the prevention of stress, which are termed primary (e.g., stressor reduction), secondary (e.g., stress management) and tertiary (e.g., employee assistance program/workplace counseling) levels of prevention, and address different stages in the stress process $^{24)}$. First, tertiary stress prevention program focused on the treatment and rehabilitation should be provided to those individuals who have suffered or are suffering from serious ill health as a result of stress. It is enabled by providing counseling services for employee problems in the work or personal domain. Second, since female doctors had higher burnout than any other health professionals, they should be considered more in the secondary prevention program. Increasing awareness and improving the stress management skills of the individual through training and educational activities is also one of the options for prevention. Lastly, the elimination of sources of stress inherent in the work environment as a primary prevention program is also recommended to hospitals in order to reduce their negative impact on the individual professionals.

This study has the following limitations. First, our sample was collected from only doctors and nurses in clinical (tertiary setting) and district health care centers (secondary setting), and excluded those of primary health care clinics, and therefore it was not possible to generalize the conclusions for all doctors and nurses in Mongolia. To obtain a more general picture of the conditions of Mongolian health professionals, further studies should include more doctors and nurses from primary health care clinics. Second, R-square for client-related burnout (0.18) was lower than other burnout dimensions and only ERI was significant factor. This showed that there may be other factors influencing clientrelated burnout. In the future study, other factors such as patient characteristics should be included in order to improve explanatory power of the regression model on client-related burnout. Third, as it is a cross-sectional design, no causal inference can be drawn. In the future, a longitudinal study should be conducted to identify the causal factors for stress and burnout using these findings as a baseline data. Fourth, since both burnout (dependent variable) and stress (independent variable) were perceptual measures derived from the same respondent, there is a possibility of common method variance (CMV) which causes systematic measurement errors that either inflate of deflate the observed relationships between constructs, generating both Type I and Type II errors ${ }^{25)}$. To avoid any potential CMV in the future study, burnout measures should be constructed using information from different source (e.g. burnouts are measured by supervisor or colleague) than the stress measures. Further, as Chang et al. ${ }^{25)}$ suggest, the order the questions should be mixed in order to reduce the likelihood of CMV. Finally, the present study result is restricted to the ERI model, which is supported by a body of evidence, while several concepts of psychosocial work-related stress have been developed ${ }^{26)}$. 


\section{References}

1) O'Rourke M, Mira M, Orgil B, Jeugmans M (2003) Developing family medicine in Mongolia. Asia Pac Fam Med 2, 65-70.

2) Bruun O, Ronnas P, Narangoa L (1999) Country analysis Mongolia: transition from the second world to the third? Essner J (Ed.), Nordic Institution of Asian Countries Stockholm

3) Ministry of Health (2009) Implementing agency of the Government of Mongolia. Department of Health. Healthcare indicator.

4) Ministry of Health, UNDP, School of Public Health (2010) Final report of development of guidelines for introducing differentiated payment systems based on labor norms, workload standard for health professionals in Mongolia. Sod Press, Ulaanbaatar.

5) Simpson LA, Grant L (1991) Sources and magnitude of job stress among physicians. J Behav Med 14, 27-42.

6) Felton JS (1998) Burnout as a clinical entity- its importance in health care workers. J Occup Health 48, 237-50.

7) Iacovides A, Fountoulakis KN, Kaprinis ST, Kaprinis G (2003) The relationship between job stress, burnout and clinical depression. J Affec Disord 75, 209-21.

8) European Commission (2000) Guidance on workrelated stress. Spice of life, or kiss or death? Office for Official Publications of the European Commission, Luxemburg.

9) Härmä M, Kompier, MAJ, Vahtera J (2006) Work related stress and health- risks, mechanisms and counter-measures. Scand J Work Environ Health 32, 413-9.

10) Higashiguchi K, Morikawa $Y$, Miura K, Nishijo M, Tabata M, Yoshita K, Sagara T, Nakagawa H (1998) The development of the Japanese version of the Maslach Bunout Inventory and the examination of the factor structure. Nippon Eisegaku Zasshi 53, 447-55.

11) Kristensen TS, Borritz M, Christensen KB (2005) The Copenhagen Burnout Inventory: a new tool for the assessment of burnout. Work \& Stress 19, 192-207.

12) Watanabe M, Tanaka K, Aratake K, Kato N, Sakata $Y$ (2008) The impact of effort-reward imbalance on quality of life among Japanese working men. Ind Health 46, 217-22.
13) Siegrist J (1996) Adverse health effects of high effort/ low reward conditions. J Occup Health Psychol 1, 27-41.

14) Shimizutani M, Odagiri Y, Ohya Y, Shimomitsu T (2008) Relationship of nurse burnout with personality characteristics and coping behaviors. Ind Health 46, 326-35.

15) Tsutsumi A (2004) A review of empirical studies on the model of effort reward imbalance at work: reducing occupational stress by implementing a new theory. Soc Sci Med 59, 2335-59.

16) Li J, Yang W, Cheng Y, Siegrist J, Cho SI (2005) Effort reward imbalance at work and job dissatisfaction in Chinese health care workers: a validation study. Int Arch Occup Environ Health 78, 198-204.

17) Odagiri Y, Shimomitsu T, Ohay Y, Kristensen TS (2004) Overcommitment and high effort are strongly associated with burnout among Japanese nurses. Int J Behav Med 11 (Suppl), 214.

18) Tsai F, Chan CH (2010) Occupational stress and burnout of judges and procurators. Int Arch Occup Environ Health 83, 133-42.

19) Hasselhorn H, Peter T, Peter R (2004) Effort reward imbalance among nurses in stable countries and in countries in transition. Int $\mathrm{J}$ Occup Environ Health 10, 401-8.

20) Sugarmaa M, Lhagvasuren TS (2010) Job stress and health risk among Mongolian government administrative employees. Mongol J Health Sci 7, 38-44.

21) Sugarmaa M, Purevsuren D, Lhagvasuren TS (2008) Impact of psychosocial work environment on health status of Mongolian civil servants. Health Sci 9, 3-7.

22) Winwood P, Winefeld AH (2004) Comparing two measures of burnout among dentists in Australia. Int J of Stress Manage 11, 282-9.

23) Cooper CL, Cartwright S (1997) An intervention strategy for workplace stress. J Psycho Res 43, 7-16.

24) Cooper C (1998) Theories of organizational stress. Oxford University Press, Oxford.

25) Chang SJ, Witteloostuijin AV, Eden L (2010) From editors: common method variance in international business research. J Int Busi Studies 41, 178-84.

26) Borritz M (2005) Burnout in human service workcauses and consequences. Results of 3-years follow up of the PUMA-study among human service workers in Denmark. Ph.D. thesis. 